\title{
PENGARUH VARIASI FLY ASH SEBAGAI PENGGANTI SEBAGIAN SEMEN DENGAN COPPER SLAG PENGGANTI SEBAGIAN PASIR UNTUK BETON MUTU 42 MPA
}

\author{
Ferdian Adhitia $^{1)}$ dan Dewi Pertiwi ${ }^{1)}$
}

1) Jurusan Teknik Sipil, Institut Teknologi Adhi Tama Surabaya, Jawa Timur

ferdianadhitia@gmail.com

\begin{abstract}
At the smelting plant of PT Smelting Company Gresik produces waste in the form of copper slag. Copper slag waste has several advantages including increasing concrete compressive strength, reducing heat hydration, increasing resistance to sulfate in seawater, reducing alkali-silica and chloride attack. Probolinggo power plant there is the waste product from burning coal. The waste is divided into two types. The flying waste is fly ash obtained by being captured by other particle filtration equipment before the exhaust gas reaches the coal chimney. Whereas the waste that goes down is called bottom ash. This study uses copper slag waste as a partial replacement for sand with fly ash as a partial replacement for cement. The variant used are 40\% copper slag, $40 \%$ copper slag $+5 \%$ fly ash, 40\% copper slag $+7.5 \%$ fly ash, 40\% copper slag $+10 \%$ fly ash. Copper slag comes from PT. Smaleting Company Gresik, while the fly ash from PT. Paiton. Tests carried out at PT. SCG Readymix. Test carried out at the age of 14 days, 28 days and 56 days. Normal concrete compressive strength was obtained more than $42 \mathrm{MPa}$, the highest compressive strength at a variation of $40 \%$ copper slag $+10 \%$ fly ash with compressive strength of $58.13 \mathrm{MPa}$ at the age of 56 days.
\end{abstract}

Keywords: copper slag, fly ash, compressive strength 


\begin{abstract}
ABSTRAK
Pada pabrik peleburan tembaga PT Smelting Company Gresik meghasilkan limbah berupa copper slag. Limbah copper slag memiliki beberapa keuntungan antara lain meningkatkan kuat tekan beton,mengurangi panas hidrasi, meningkatkan ketahanan terhadap sulfat dalam air laut, mengurangi serangan alkali-silika dan klorida. Pada PLTU Paiton Probolinggo terdapat hasil limbah dari pembakaran batu bara. Limbah tersebut terbagi dua. Limbah yang terbang tersebut adalah fly ash yang didapatkan dengan cara ditangkap oleh peralatan filtrasi partikel lain sebelum gas buang mencapai cerobong asap batu bara. Limbah yang turun kebawah disebut bottom ash. Penelitian ini menggunakan limbah copper slag sebagai pengganti sebagian pasir dengan fly ash pengganti sebagian semen. Variasi yang digunakan adalah $40 \%$ copper slag, $40 \%$ copper slag $+5 \%$ fly ash, $40 \%$ copper slag $+7.5 \%$ fly ash, $40 \%$ copper slag $+10 \%$ fly ash. Copper slag berasal dari PT. Smelting Company Gresik, sedangkan fly ash dari PT. Paiton.Pengujian dilakukan di PT. SCG Readymix. Pengujian dilakukan pada umur 14 hari, 28 hari, dan 56 hari. Kuat tekan beton normal diperoleh melebihi 42 Mpa, dimana kuat tekan tertinggi pada variasi $40 \%$ copper slag $+10 \%$ fly ash dengan kuat tekan 58.13 MPa pada umur 56 hari.
\end{abstract}

Kata kunci: terak tembaga, abu terbang, kuat tekan 


\section{PENDAHULUAN}

Beton mutu tinggi sangat diperlukan untuk mendukung struktur utama pada bangunan gedung misalnya kolom struktural, balok induk, shearwall, dan lain-lain.

Pada pabrik peleburan tembaga PT. Smelting Company Gresik meghasilkan limbah berupa copper slag. Limbah copper slag memiliki beberapa keuntungan antara lain meningkatkan kuat tekan beton,mengurangi panas hidrasi, meningkatkan ketahanan terhadap sulfat dalam air laut, mengurangi serangan alkali-silika dan klorida.

Pada PLTU Paiton Probolinggo terdapat hasil limbah dari pembakaran batu bara. Limbah yang terbang tersebut adalah fly ash yang didapatkan dengan cara ditangkap oleh peralatan filtrasi partikel lain sebelum gas buang mencapai cerobong asap batu bara.

.Pada penelitian ini memanfaatkan fly ash sebagai bahan pengisi dan copper slag sebagai pengganti sebagian pasir untuk campuran beton mutu tinggi dengan kuat tekan rencana $42 \mathrm{MPa}$.

\section{KAJIAN PUSTAKA}

\subsection{Penelitian Terdahulu}

Sebayang (2010) melakukan penelitian memanfaatkan limbah fly ash dengan variasi $0 \%, 3 \%, 6 \%, 9 \%, 12 \%$, dan $15 \%$. Kuat tekan yang dihasilkan pada umur 28 hari tertinggi pada variasi $9 \%$ sebesar $41.882 \mathrm{MPa}$.

Karimah (2016) melakukan penelitian dengan memanfaatkan limbah copper slag. Kuat tekan rencana $25 \mathrm{MPa}$. Variasi yang digunakan adalah 0\%, 20\%, $40 \%, 60 \%, 80 \%$ dan $100 \%$. Kuat tekan tertinggi pada variasi $60 \%$ copper slag sebesar $42.73 \mathrm{MPa}$.

Mauladi (2014) melakukan penelitian dengan memanfaatkan limbah industri copper slag sebagai pengganti pasir untuk campuran beton. Kuat tekan rencana sebesar $18.675 \mathrm{MPa}$. Variasi copper slag yang digunakan 0\%, 10\%, 20\%, 30\%, dan 35\%. Dari hasil penelitian didapatkan nilai kuat tekan tertinggi pada umur 28 hari 29.237 $\mathrm{MPa}$ pada variasi copper slag $30 \%$.

\subsection{Limbah Copper Slag (CS)}

Limbah copper slag merupakan hasil dari sisa peleburan tembaga. Limbah ini memiliki bentuk yang hampir sama dengan pasir alami. Limbah tersebut harus ada pengelolahan agar tidak mencemari lingkungan. Oleh karena itu pemanfaatan limbah ini sangat diperlukan.

Keuntungan dari penggunaan copper slag: 
1. Meningkatkan kuat tekan beton.

2. Meningkatkan ketahanan terhadap sulfat dala $\mathrm{m}$ air laut.

3. Menurunkan suhu dan memperkecil porositas.

4. Tidak bersifat korosif terhadap tulangan beton.

5. Kandungan $\mathrm{SiO}_{2}$ ketika bereaksi dengan semen akan menjadi bahan perekat yang kuat.

\subsection{Fly Ash (FA)}

Limbah fly ash adalah salah satu limbah dari sisa pembakaran batu bara. PLTU Paiton menggunakan batu bara sebagai bahan utama. Sehingga banyak menghasilkan limbah batu bara. Batu bara menghasilkan 2 limbah yaitu fly ash dan bottom ash. Fly ash didapat dengan cara ditangkap oleh alat filtrasi partikel sebelum gas buang ke cerobong asap. Sedangkan bottom ash limbah yang turun kebawah. Komposisi abu batu bara terdiri dari fly ash 80-90\% dan bottom ash 10-20\%. Terdapat 3 kelas yang berbeda, yaitu (Mulyono, 2010):

1. Fly ash kelas $\mathrm{F}$

Fly ash kelas F merupakan fly ash yang mengandung $\mathrm{CaO}$ lebih kecil dari 10\% yang dihasilkan dari pembakaran antrasit atau bituminus batubara.

\section{Fly ash kelas $\mathrm{C}$}

Fly ash ini disebut juga dengan high-calcium fly ash. Fly ash kelas ini memiliki kadar $\mathrm{CaO}$ yang tinggi, sehingga memiliki sifat cementisius.

3. Fly ash kelas $\mathrm{N}$

Fly ash ini memiliki sifat pozzolan yang baik.

\subsection{Kuat Tekan Beton}

Kuat tekan beton adalah perbandingan antara tingkatan beban yang diberikan dengan luas penampang. Faktorfaktor yang mempengaruhi hasil dari kuat tekan beton antara lain material, metode yang digunakan, tata pelaksanaan pembuatan beton, dan perawatan.

Nilai kuat tekan beton didapatkan dengan cara pengujian standar yaitu memberikan beban tekan bertingkat dengan kecepatan peningkatan beban tertentu terhadap benda uji. nilai kuat tekan beton yang dinyatakan dalam MPa atau $\mathrm{kg} / \mathrm{cm}^{2}$. Tata cara pengujian pada umumnya memakai standar ASTM C.39 atau sesuai yang diisyaratkan oleh PBI 1989. Rumus yang digunakan untuk perhitungan kuat tekan beton adalah:

$\mathrm{f}^{\prime}{ }_{\mathrm{c}}=\mathrm{P} / \mathrm{A}$

dimana:

$\mathrm{f}^{\prime}{ }_{\mathrm{c}}=$ kuat tekan beton $(\mathrm{MPa})$

$\mathrm{P}=$ Beban maksimum $(\mathrm{kN})$ 

$\mathrm{A}=$ luas penampang benda uji $\left(\mathrm{mm}^{2}\right)$

\section{METODE PENELITIAN}

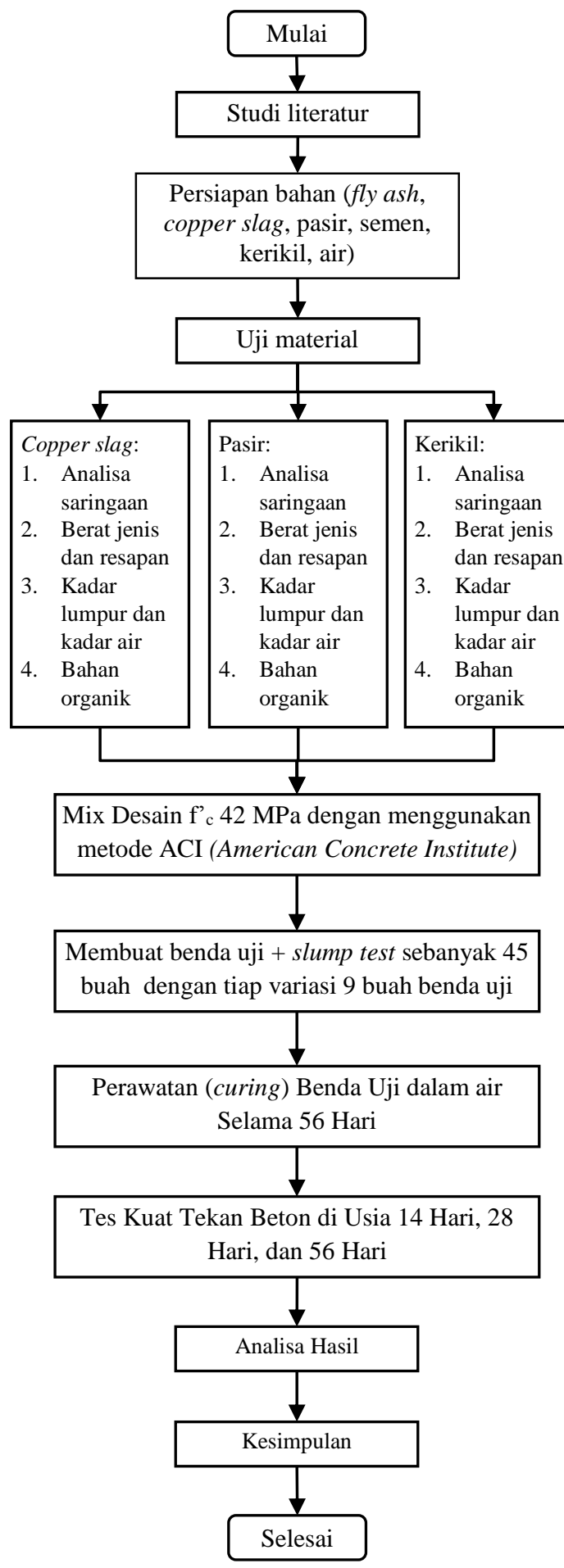

Gambar 1. Alur Penelitian

\section{HASIL DAN PEMBAHASAN}

Tabel 1 menunjukkan kuat tekan beton pada umur 14 hari, dimana semakin banyak prosentase fly ash yang digunakan, kuat tekan beton mengalami peningkatan.

\section{Tabel 1. Kuat Tekan pada Umur 14 hari}

\begin{tabular}{ccc}
\hline Variasi & $\begin{array}{c}\text { Kuat } \\
\text { tekan } \\
\left(\mathrm{N} / \mathrm{mm}^{2}\right)\end{array}$ & $\begin{array}{c}\text { Kuat tekan } \\
\text { rata rata } \\
\left(\mathrm{N} / \mathrm{mm}^{2}\right)\end{array}$ \\
\hline Beton Normal & 32.27 & 30.86 \\
& 29.44 & \\
$40 \% \mathrm{CS}+0 \% \mathrm{FA}$ & 34.54 & \\
& 33.97 & 34.16 \\
& 33.97 & \\
$40 \% \mathrm{CS}+5 \% \mathrm{FA}$ & 34.54 & \\
& 35.10 & 36.42 \\
$40 \% \mathrm{CS}+7.5 \%$ & 39.63 & \\
$\mathrm{FA}$ & 35.67 & \\
& 38.50 & \\
& 41.33 & \\
$40 \% \mathrm{CS}+10 \% \mathrm{FA}$ & 38.50 & 39.82 \\
& 39.63 & \\
\hline
\end{tabular}

Tabel 2. Kuat Tekan Rata-Rata 28 hari

\begin{tabular}{ccc}
\hline Variasi & $\begin{array}{c}\text { Kuat } \\
\text { tekan } \\
\left(\mathrm{N} / \mathrm{mm}^{2}\right)\end{array}$ & $\begin{array}{c}\text { Kuat tekan } \\
\text { rata rata } \\
\left(\mathrm{N} / \mathrm{mm}^{2}\right)\end{array}$ \\
\hline \multirow{3}{*}{ Beton Normal } & 39.63 & \\
& 39.63 & 39.44 \\
& 39.06 & \\
$40 \% \mathrm{CS}+0 \% \mathrm{FA}$ & 40.76 & \\
& 41.33 & 41.14 \\
& 41.33 & \\
$40 \% \mathrm{CS}+5 \% \mathrm{FA}$ & 42.46 & \\
& 42.46 & 42.65 \\
& 43.03 & \\
$40 \% \mathrm{CS}+7.5 \% \mathrm{FA}$ & 43.59 & \\
& 42.46 & 43.22 \\
& 43.59 & \\
$40 \% \mathrm{CS}+10 \% \mathrm{FA}$ & 44.73 & \\
& 53.78 & 47.93 \\
& 45.29 & \\
\hline
\end{tabular}


Tabel 2 menunjukka kuat tekan beton normal pada umur 28 hari belum mencapai kuat tekan beton rencana karena agregat kasar yang digunakan hanya satu jenis yaitu ukuran 10-20 mm, sehingga masih terdapat rongga pada beton. Pada variasi $40 \% C S+0 \% F A$ kuat tekan hampir mencapai target kuat tekan rencana.

Tabel 3. Kuat Tekan Rata-Rata 56 hari

\begin{tabular}{ccc}
\hline Variasi & $\begin{array}{c}\text { Kuat } \\
\text { tekan } \\
\left(\mathrm{N} / \mathrm{mm}^{2}\right)\end{array}$ & $\begin{array}{c}\text { Kuat tekan } \\
\text { rata rata } \\
\left(\mathrm{N} / \mathrm{mm}^{2}\right)\end{array}$ \\
\hline Beton Normal & 42.46 & 42.74 \\
& 43.03 & \\
$40 \% \mathrm{CS}+0 \% \mathrm{FA}$ & 44.26 & \\
& 46.99 & \\
& 50.39 & \\
$40 \%$ CS+5\% FA & 50.39 & 48.31 \\
& 44.16 & \\
$40 \%$ CS+7.5\% & 49.26 & \\
FA & 52.65 & 51.71 \\
& 53.22 & \\
$40 \%$ CS+10\% FA & 55.48 & \\
& 61.75 & 58.13 \\
\hline
\end{tabular}

Dari Tabel 3 diketahui bahwa kuat tekan beton dengan variasi mulai $40 \%$ CS $+0 \%$ FA pada umur 56 hari mencapai kuat tekan beton diatas $42 \mathrm{MPa}$.

Gambar 2 menunjukkan bahwa pada umur 28 hari kuat tekan yang menggunakan variasi limbah copper slag dan fly ash mengalami peningkatan kuat tekan beton disbanding kuat tekan beton teoritis. Hal tersebut dikarenakan limbah copper slag mengandung silika serta kandungan besi yang lebih tinggi dari pasir. Selain itu copper slag juga berfungsi sebagai filler untuk mengisi rongga beton. Penggunaan variasi CS $40 \%+$ FA $10 \%$ menghasilkan kuat tekan beton tertinggi.

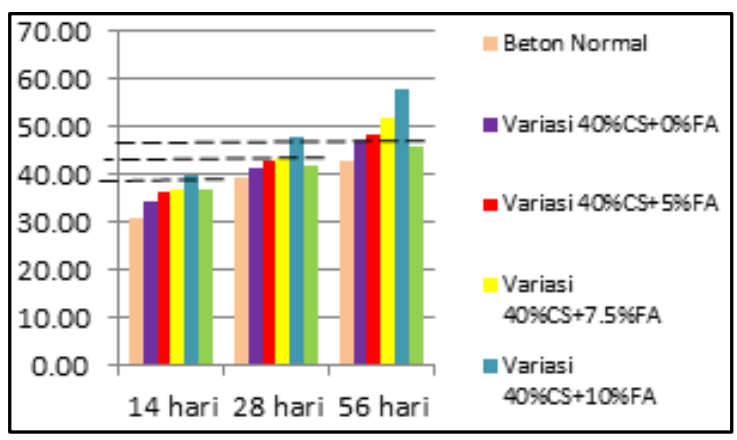

Gambar 2. Perbandingan Kuat Tekan Beton

\section{SIMPULAN DAN SARAN}

\subsection{Simpulan}

Berdasarkan hasil penelitian didapatkan beberapa kesimpulan:

1. Berdasarkan hasil pengujian kuat tekan beton pada umur 56 hari dengan menggunakan limbah copper slag sebagai pengganti sebagian pasir dan limbah fly ash didapatkan hasil kuat tekan beton diatas kuat tekan beton rencana $42 \mathrm{MPa}$. Kuat Tekan beton dengan variasi $40 \% \mathrm{CS}+0 \% \mathrm{FA} 46.8 \mathrm{MPa}$, $40 \% \mathrm{CS}+5 \%$ FA $48.31 \mathrm{MPa}$, 
$40 \% \mathrm{CS}+7.5 \% \mathrm{FA} 51.71 \mathrm{MPa}$, $40 \% \mathrm{CS}+10 \%$ FA $58.13 \mathrm{MPa}$.

2. Perbandingan kuat tekan beton normal dengan kuat tekan beton yang menggunakan variasi limbah copper slag dan limbah fly ash. Kuat tekan mengalami peningkatan berturut turut pada variasi $40 \% \mathrm{CS}+0 \% \mathrm{FA}$, variasi $40 \% \mathrm{CA}+5 \% \mathrm{FA}$, variasi $40 \% \mathrm{CS}+7.5 \% \mathrm{FA}$, variasi $40 \% \mathrm{CS}+10 \% \mathrm{FA}$ sebesar $9.499 \%, \quad 13.032 \%$, $20.987 \%, \quad 36.008 \%$ terhadap beton normal.

3. Nilai FAS berpengaruh terhadap kuat tekan beton. Kuat tekan tertinggi pada variasi $40 \%$ copper slag $+10 \%$ fly ash menggunakan nilai FAS 0.4.

\subsection{Saran}

Untuk penelitian yang lebih lanjut disarankan:

1. Perlu adanya penelitian lebih lanjut dengan penambahan variasi limbah, nilai FAS disamakan, serta penambahan zat aditif.

2. Sebelum dilakukan pengujian kuat tekan, harus memperhatikan beberapa hal seperti pengangkatan benda uji dari tempat curring, capping beton agar menghasilkan kuat tekan yang maksimal.

\section{DAFTAR PUSTAKA}

Anonim. ASTM C39 Standard Test Methods for Compressive Strength of Cylindrical Concrete Specimens.

Karimah, R. (2016). Kajian Penggunaan Copper Slag Sebagai Agregat Halus Beton. Universitas Muhammadiyah Malang.

Mauladi, M.S. (2014). Pemanfaatan Copper Slag Sebagai Substitusi Pasir Pada Campuran Beton Mutu $K$-225. Tugas Akhir, Jurusan Teknik Sipil Universitas Sriwijaya.

Mulyono, T. (2004). Teknologi Beton. ANDI: Yogyakarta.

Panitia Pembaharuan Peraturan Beton Bentulang Indonesia. (1971). Peraturan Beton Bertulang Indonesia. Bandung: Departemen Pekerjaan Umum dan Tenaga Listrik.

Sebayang, S. (2010). Pengaruh Kadar Abu Terbang Sebagai Pengganti Sejumlah Semen Pada Beton Alir Mutu Tinggi. Tugas Akhir, Jurusan Teknik Sipil Universitas Lampung. 